\title{
EL CONTROL DE LA REPRESENTATIVIDAD ADECUADA DE LAS ASOCIACIONES DE CONSUMIDORES EN EL EJERCICIO DE LAS ACCIONES COLECTIVAS*
}

\author{
Maite Aguirrezabal Grünstein**
}

\author{
RESUMEN
}

El presente trabajo tiene por objeto analizar a la luz de la doctrina y el Derecho comparado la novedosa institución de la representatividad adecuada, propia de los procedimientos colectivos. Se estudia su regulación en la legislación chilena de protección del consumidor, en especial la representación que corresponde a las asociaciones de consumidores y usuarios y se efectúa un análisis del criterio que la Corte Suprema ha sentado en fallos recientes sobre la materia.

\section{REPRESENTACIÓN ADECUADA - CONSUMIDORES - LEGITIMACIÓN}

\section{Exercise of collective actions: Analysis of the recent jurisprudence of our Supreme Court}

\begin{abstract}
The present paper has the objective of analyzing in light of doctrine and comparative law the innovative institution of adequate representation, peculiar to collective procedures. Its regulation in the Chilean Consumer Protection Act is studied, especially the corresponding representation of consumer and user associations, as well as the Supreme Court's criteria in the recent rulings regarding the subject.
\end{abstract}

\section{ADEQUATE REPRESENTATION- CONSUMERS - LEGITIMATION}

* El presente trabajo se elabora en el marco del Proyecto FONDECYT n ${ }^{\circ} 11080052$, titulado "Análisis crítico del procedimiento contemplado en la Ley $\mathrm{N}^{\circ} 19.496$, para la defensa de los intereses colectivos y difusos de consumidores y usuarios”, del que la autora es la investigadora responsable.

** Abogada, Doctora en Derecho, Profesora de Derecho Procesal en la Universidad de los Andes, Santiago de Chile, maguirrezabal@uandes.cl

Artículo recibido el $1^{\circ}$ de junio de 2010 y aceptado para su publicación por el Comité Editorial el 27 de octubre de 2010 . 


\section{INTRODUCCIÓN}

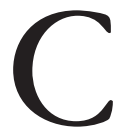

omo consecuencia del surgimiento de los intereses supraindividuales, aparecen y se desarrollan cuerpos sociales intermedios que organizadamente pueden conseguir de modo más efectivo la satisfacción de intereses o la consecución de fines que el ciudadano no puede obtener de modo aislado ${ }^{1}$, porque los obstáculos en el acceso a la justicia les afectan con menor intensidad, y gozan de una mayor disponibilidad frente a las exigencias de la tutela de estos intereses.

El problema de la legitimación para accionar en defensa de intereses colectivos y difusos es en lo cronológico anterior al de la cosa juzgada, pero se encuentra estrechamente vinculada a la misma. Lo anterior se explica porque los efectos erga omnes que produce la sentencia dictada en un procedimiento colectivo requiere que los intereses hayan sido adecuadamente "representados en juicio", puesto que la sentencia afectará a quienes hayan sido parte en el proceso pero también producirá sus efectos respecto de aquellos consumidores que no hayan efectuado intervención alguna.

De ahí entonces que una vez reconocida por el legislador la necesidad de proteger los intereses supraindividuales, queda pendiente la cuestión fundamental de determinar a quién se atribuye la cualidad para solicitar la protección jurisdiccional de dichos intereses.

Sin perjuicio de que la figura de la representación adecuada se encuentra inserta en las legislaciones de todos los países en materia de procedimientos colectivos, se trata de una institución de la que se tiene escasas nociones.

¿Qué recaudos debe cumplir quien invoque actuar en nombre de quienes no participan en el proceso? Se trata de una pregunta efectivamente relevante, y la respuesta debe velar por la no afectación de los derechos de aquellos que no han sido escuchados durante el proceso, pero que igual pueden verse afectados por una sentencia cuyos efectos sean erga omnes. Es una de las claves sobre las que un proceso colectivo se articula. Cuantas más certezas encontremos sobre la capacidad del representante para hablar por aquellos que no intervienen directamente en el proceso, mayor será la legitimidad de la sentencia que en dicho proceso se pronuncie.

Los efectos de la sentencia que se dicte en un proceso de esta naturaleza adquiere la cualidad de cosa juzgada para el representante y todos los miembros del grupo, sin importar si el resultado obtenido es favorable o desfavorable. Esto significa que, gane o pierda el pleito, la discusión dada por el representante precluirá toda posibilidad de litigar de nuevo, tanto colectiva como individualmente. Como puede advertirse, este

${ }^{1}$ Cfr. Gutiérrez de Cabiedes, P., Artículo 11. Legitimación para la Defensa de Derechos de Consumidores y Usuarios, en Cordón Moreno, F. (coord.), Comentarios a la Ley de Enjuiciamiento Civil, Aranzadi, Navarra, 2001, p. 152. En este mismo sentido Navarro Hernán, M., Partes, legitimación y litisconsorcio en el proceso civil, Colex, Madrid, 1998, p. 140, para quien "la debilidad del consumidor en las relaciones de mercado, unida a la desproporción entre los gastos que el proceso lleva consigo y las ventajas o utilidades que puede obtener mediante el mismo, en la práctica conduce a que el consumidor individual en contadas ocasiones decida iniciar él solo un proceso. En consecuencia, el fortalecimiento de su posición ha determinado la atribución de la legitimación activa a favor de las asociaciones de consumidores, en aras de una protección más eficaz de los intereses de éstos". 
mecanismo procesal reviste carácter excepcional, por dos razones fundamentales. En primer lugar, porque su empleo implica una seria limitación a la autonomía individual de los sujetos afectados ${ }^{2}$. En segundo lugar, porque su utilización implica también una redefinición de la idea clásica de debido proceso legal. Este tipo de sistema procesal colectivo descansa sobre la ficción de considerar presentes en el debate a los integrantes del grupo a través de un representante que, como ya fue señalado, no escogieron voluntariamente. Es por ello que el derecho a ser oído por el juez se limita aquí a ser oído a través de tal atípico gestor de intereses ajenos.

Así, ante un cuadro de situación que se presenta como excepcional y que acarrea serias consecuencias a gran cantidad de personas, es evidente la necesidad de establecer algún mecanismo de control para evitar que los titulares de los derechos ejercidos por el representante (esto es, los miembros del grupo representado) puedan ver perjudicada su situación por una sentencia judicial dictada en el marco de un proceso en el cual -al menos en principio- no participarán en modo alguno ${ }^{3}$.

\section{TRATAMIENTO DE LA REPRESENTATIVIDAD ADECUADA EN LA DOGMÁTICA Y EN EL DERECHO COMPARADO}

\subsection{Importancia de distinguir la representación de las situaciones legitimantes}

Suele confundirse la legitimación colectiva con situaciones de representación, señalándose que la utilización de técnicas procesales que permitan la accionabilidad conjunta de posiciones individuales hace necesaria la existencia de un ente exponencial o de un representante, porque aunque cada miembro del grupo tenga personalidad propia, la colectividad por sí misma no puede actuar en el proceso por carecer de personalidad jurídica ${ }^{4}$.

${ }^{2}$ Tidmarsh, J., "Rethinking Adequacy of Representation”, 87 Tex. L. Rev., p. 1137. Nótese que, entre otras cosas, los miembros del grupo ya no podrán escoger si llevar adelante o no su caso en sede judicial, ni mucho menos con qué abogado hacerlo, cuándo ni dónde, cómo presentar sus argumentos, etc.

3 "Hansberry vs. Lee", 311 US 32 1940. Al dictar sentencia en esta causa, el tribunal recordó el principio general de que nadie puede ser obligado personalmente por una decisión dictada en el marco de un proceso en el cual no participó, y que la eventual ejecución de una sentencia del género contra un sujeto ausente en el pleito donde ella fue dictada vulneraría la garantía de debido proceso establecida en la $5^{\text {a }}$ y la $14^{\text {a }}$ Enmiendas de la Constitución. Sentado ello, recordó la reconocida excepción a tal principio, configurada por las decisiones tomadas en procesos representativos o de clase; y apuntó que dichas sentencias sólo pueden afectar a los miembros ausentes con cualidad de cosa juzgada en la medida en que: i) el procedimiento para obtenerlas esté diseñado y aplicado de modo que asegure que los miembros presentes son de la misma clase que los ausentes y ii) el litigio sea conducido de forma tal que asegure la completa y justa consideración de las cuestiones comunes. Distintos análisis y lecturas sobre los alcances del fallo pueden consultarse en Subrin, S., "Civil Procedure. Doctrine, practice, and Context", Aspen Law E Bussines, New York, 2000, p. 906 y ss.; Tidmarsh, Jay, "Rethinking Adequacy...", op. cit., p. 1137.

${ }^{4}$ Cfr. Bujosa Vadell, L., La protección jurisdiccional de los intereses de grupo, Bosch, Barcelona, 1995, pp. 161 y ss. 
La doctrina y la jurisprudencia también se han referido a este tema, y se ha dicho que esta exigencia surge como consecuencia de "la necesidad, señalada desde los inicios del tratamiento doctrinal de este tema, de recurrir a nuevos conceptos, estructuras y mecanismos para la defensa de los intereses que conciernen a enteras categorías o grupos de personas, superando los propios de una concepción tradicional del proceso; y, entre ellos, el de la vieja concepción, excesivamente restrictiva e individualista de la legitimación para demandar" 5 .

La figura de la representatividad adecuada no queda comprendida dentro del concepto tradicional de representación procesal, por cuanto en esta última la calidad de parte se predica del representado y no del representante, ya que supone una actuación en nombre de otro, producida de manera tal que los efectos jurídicos del acto derivan siempre de modo directo en la esfera jurídica del representado y nunca en la del representante. En cambio, en la primera, la representación adecuada coincide con la figura de la legitimación, en el sentido que el representante es parte en el proceso por tener una posición determinada frente al objeto litigioso y un interés en el mismo, es decir, es también titular de la relación jurídica sustancial deducida en juicio.

Se plantea entonces la necesidad de construir un concepto totalmente nuevo de legitimación, ideológica más que jurídica: de allí que surja el concepto de ideological plaintiff o demandante ideológico, que porta el interés colectivo, de grupo o de clase, y que se funda en la necesidad de superación del garantismo individualista y de nacimiento de un nuevo tipo, social o colectivo, concebido como salvaguardia, no sólo del individuo en un proceso individualista, sino de los nuevos grupos y cuerpos intermedios.

Para evitar abusos, el portador deberá ser cualificado o sometido a una selección. Debe ostentar una "representatividad adecuada" 6 , de manera que si la parte ideológica

\footnotetext{
${ }^{5}$ Cfr. en este sentido, Bujosa Vadell, L., "Artículo 11. Legitimación para la defensa de derechos e intereses de consumidores y usuarios”, en Gómez de Liaño González, F. (coord.), La Ley de Enjuiciamiento Civl, Fórum, Oviedo, 2000, p. 75, para quien la solución de la representatividad adecuada puede ir por dos caminos: en el ámbito del Derecho continental se ha privilegiado la actuación de asociaciones en defensa de los intereses de grupo, las cuales deben cumplir una serie de criterios fijos legislativamente. En el Derecho anglosajón en cambio y de manera específica en la regulación de los EE.UU., se produce con claridad un aumento de los poderes del juez que, no obstante, debe aplicar unos criterios establecidos en la Rule 23 (a 4) FRCP.

${ }^{6}$ Bujosa Vadell, Lorenzo, La protección..., op. cit., p. 186 señala que esta figura "se fundamenta en la no aplicación a situaciones nuevas de carácter y relevancia colectiva soluciones referidas a situaciones individualistas de contenido esencialmente patrimonialista" para agregar luego que "permite valorar la representatividad de la persona que actúa ante los tribunales en defensa de intereses de grupo no organizados sólo parcialmente". Son muchas las legislaciones que han adoptado este principio. Famoso es el caso francés y su Loi Royer, que dispone que las asociaciones de consumidores regularmente declaradas como teniendo expreso objeto estatutario la defensa de intereses de los consumidores, si son autorizadas a tal fin pueden ejercitar acciones civiles ante cualquier jurisdicción en todos los casos que involucren "hechos que directa o indirectamente provoquen detrimento a los intereses colectivos de los consumidores", pero para ello, la asociación debe estar debidamente certificada, teniendo el Ministerio Público el deber de ayudar a asegurar que esta certificación sólo se conceda a las asociaciones que son "representativas" de los consumidores a la luz del sistema francés. Este término de la representatividad adecuada nace de un equívoco conceptual, porque se construye a partir del de la "adequacy of representation", concepto que emana de la institución de las class actions, sistema adoptado por legislaciones como la brasileña o la norteamericana.
} 
es representativa de toda la clase o grupo a la que aquel interés corresponde, será perfectamente legítimo que el proceso desarrolle sus efectos también respecto de las partes ausentes ${ }^{7}$.

\subsection{La norma de representatividad adecuada en el Derecho Comparado}

Esta norma ha sido recogida de legislaciones con tradición de Civil Law y en los que los procesos colectivos se ventilan a través de las class actions.

En sistemas como el estadounidense o el brasileño, el término "representación" no se entiende para estos efectos del modo tradicional, sino que se considera representantes "a los legitimados por el derecho positivo de un país para entablar un pleito colectivo en beneficio del grupo titular del derecho difuso, colectivo o individual homogéneo”, y en que representante es el portador en el juicio de los intereses del grupo" 8 .

En los Estados Unidos, los requisitos de la acción colectiva se encuentran establecidos en la Regla 23 de las Reglas Federales de Procedimientos Civiles, que exige la impractibilidad del litis consorcio, que la situación permita una decisión unitaria, que exista tipicidad respecto de las peticiones del grupo, lo que se conoce como typicality of claims or defenses y, por último, una adecuada representación. A diferencia de lo que ocurre en Brasil, el juez ejerce un control judicial sobre la adecuación del representante del grupo 9 , y esta adecuación es exigida por la legislación procesal civil, en lo que se conoce como el due process of law, encontrándose íntimamente ligada al derecho a un debido proceso $^{10}$. El juez debe llegar a un convencimiento pleno de que el representante del grupo puede defender adecuadamente los intereses del grupo, y, "sin duda, éste

${ }^{7}$ Cappelletti, M., "Formaciones sociales e intereses de grupo frente a la justicia civil", en Boletín Mexicano de Derecho Comparado, 83, 1995, pp. 1 y ss.

${ }^{8}$ Gidi, A. "La representación adecuada en las acciones colectivas brasileñas y el avance del Código Modelo”, Gidi A., Ferrer Mac-Gregor, E. (coords.), La tutela de los derechos difusos, colectivos e individuales homogéneos. Hacia un Código Modelo para Iberoamérica, Porrúa, México, 2003, pp. 142-143.

${ }^{9}$ Se ha señalado que esta falta de control se funda en el hecho de que la sentencia que se dicte en un proceso colectivo extenderá sus efectos secundum eventum litis, beneficiando a todos los miembros del grupo si la sentencia es favorable y, en caso contrario, los miembros del grupo pueden iniciar acciones individuales para la protección de sus respectivos intereses y derechos, no pudiendo iniciar, en todo caso, un nuevo proceso colectivo. Se ha señalado también que el legislador ya ha hecho una calificación jurídica previa sobre esta adecuación del representante al momento de establecer quiénes son los sujetos legitimados para el ejercicio de estas acciones, y que habiendo un control legislativo previo, no sería necesario un posterior control judicial.

${ }^{10}$ Señala Gidi, A., "Las acciones colectivas en los Estados Unidos", en Procesos colectivos. La tutela de los derechos difusos, colectivos e individuales un una perspectiva comparada, Porrúa, México, 2003, p. 6, que "la adequacy of representation es un corolario de la garantía del debido proceso legal, siendo considerada suficiente para asegurar la garantía de que cada miembro del grupo sea oído individualmente en juicio. En las class actions, se considera que los miembros del grupo serán oídos y estarán presentes en juicio a través de la figura del representante, que funciona como una especie de portavoz de los intereses del grupo. El derecho de ser oído en juicio se reduce entonces al derecho de ser oído a través del representante”. 
constituye el aspecto más importante de las class actions norteamericanas, tanto desde el punto de vista teórico como práctico"11.

La exigencia de una adecuada representación en el Derecho norteamericano persigue dos objetivos fundamentales: tener una visión real de los intereses del grupo e incentivar la actuación del representante de esos intereses, asegurando de esta forma que el resultado que se obtiene en el proceso colectivo sea similar al que pudo haberse obtenido en procesos iniciados individualmente por los interesados ${ }^{12}$. El juez cumple un rol fundamental en el control de esta adecuación y en el desarrollo del proceso colectivo. Adopta una posición activa en relación con el curso del proceso incluso luego de dictada la sentencia, puesto que la falta de adecuación en la representación implica que los miembros del grupo que no han sido representados adecuadamente no serán vinculados por dicha sentencia ${ }^{13}$.

La Corte Suprema de Justicia de los Estados Unidos reconoció hace ya muchos años la raíz constitucional de la referida exigencia de protección justa y adecuada de los intereses del grupo y la dogmática es conteste en que el mismo configura el pilar fundamental sobre el cual se asienta todo el sistema ${ }^{14}$. Esto último, desde dos puntos de vista: i) en términos constitucionales, por adquirir un carácter verdaderamente esencial para que la decisión no vulnere la garantía de debido proceso legal de los miembros del grupo ausentes en el debate y ii) en términos pragmáticos, porque si tal requisito se encuentra ausente en el representante o sus abogados, la decisión será inútil para desactivar el conflicto en su totalidad, ya que no podrá ser oponible a los miembros del grupo defectuosamente representados ${ }^{15}$.

Dicho esto, vale subrayar que si bien el apartado (a.4) de la FRCP 23 sólo se refiere a "los representantes" de la clase (esto es, uno o varios sujetos afectados en forma similar al resto), la jurisprudencia extendió la necesidad de controlar el requisito respecto de los abogados ${ }^{16}$.

${ }^{11}$ Gidi A., "La representación...", op. cit., pp. 147-148.

${ }^{12} \mathrm{Y}$ se compone de dos elementos fundamentales, constituidos por la ausencia de conflicto de intereses entre el representante y los miembros del grupo y la posibilidad de asegurar la tutela de esos intereses.

13 Agrega Gidi A., "La representación...", op. cit., p. 149, que "por esa razón, aunque pueda parecer contradictorio e irónico, es interés de la parte contraria al grupo velar por la adecuación del representante del grupo".

${ }^{14}$ Klonoff, R., Bilich, E., Class Actions and Other Multi-Party Litigation: Cases and Materials, West Group, 2000, p. 109; Wright, C., "Class Actions", 47 FRD 169 1970; Gidi, A., "Las acciones...", op. cit., p. 6; Fleming, J., Hazard, G., Leubsdorf, J., Civil Procedure, $5^{a}$ ed., Ed. Foundation Press, New York, 2001, apart. 10.23 .

${ }^{15}$ En este sentido, Gidi, A., Las acciones colectivas y la tutela de los derechos difusos, colectivos e individuales en Brasil. Un modelo para países de derecho civil, Instituto de Investigaciones Jurídicas, Universidad Nacional Autónoma de México, México, 2004, p. 76.

${ }^{16}$ Klonoff, R., "The Judiciary's Flawed Application of Rule 23's adequacy of representation requirement”, 2004 Mich. St. L. Rev 671, pp. 699-701. La razón de tal proceder puede encontrarse en el hecho de que los representantes de la clase son, en la inmensa mayoría de los casos, un mero instrumento de los estudios jurídicos que se dedican a litigar este tipo de asuntos. Es por ello que resulta común escuchar la afirmación de que en el sistema estadounidense el representante funciona como una llave necesaria para activar 
Esta línea jurisprudencial encontró su reflejo más profundo en la reforma que la FRCP 23 sufrió en el año 2003. Con motivo de las modificaciones introducidas en tal oportunidad, el apartado (g) de la norma impone al juez el deber de designar a quienes serán los abogados de la clase en todas las causas que certifique como colectivas, y establece una serie de estándares para considerar a efectos de proceder a tal elección. En opinión de la doctrina, si bien esta reforma configuró un importante avance en la materia, existe el riesgo de que sea interpretada como una señal de que los tribunales no deben preocuparse más por la calidad del representante de la clase. En este orden, se ha criticado la reforma por considerar que mejor hubiera sido abordar el requisito de la representatividad adecuada en general, incluyendo allí expresamente tanto a los abogados como a los representantes ${ }^{17}$.

La situación totalmente opuesta se produce en Brasil, en donde al juez le está prohibido calificar esta representación, bastando con que se corresponda con alguno de los entes legitimados que contempla el artículo 82 del Código del Consumidor ${ }^{18}$. Así, asume una actitud pasiva frente al actuar del portavoz, y la negligencia en el actuar de este último obligará al juez a dictar sentencia en contrario a los intereses del grupo al que representa.

Los miembros individuales del grupo no tienen legitimación en nombre de ese grupo, por lo que la tipicidad exigida en el Derecho norteamericano no existe en el brasileño. El legislador otorgó legitimación colectiva a entidades en reconocimiento de un interés social y no particular como en los Estados Unidos.

Para asegurar una adecuada defensa de los miembros ausentes del grupo, la ley brasileña exige que el Ministerio Público sea notificado de la admisión de cualquier acción colectiva con el objeto de que pueda hacerse parte en dichos procedimientos.

Pero, para el caso en comento, cabe distinguir situaciones en que esta inadecuación no producirá efectos tan graves, como por ejemplo si el problema se traduce en no rendir prueba suficiente, porque en este caso podrá iniciarse un nuevo proceso si se ofrece nueva prueba $^{19}$. La situación es otra si la inadecuación dice relación con la conducción

el mecanismo del proceso colectivo, no obstante lo cual quien verdaderamente actúa en tal carácter resulta ser su abogado. Cfr. en este sentido también, Gidi, A., Las acciones colectivas..., op. cit., pp. 75 y ss.

${ }^{17}$ Klonoff, R., "The Judiciary's...”, op. cit., pp. 699 y ss..

${ }^{18}$ El artículo confiere legitimación exclusiva para iniciar una acción colectiva en representación de los intereses del grupo al Ministerio Público, a la República Federal de Brasil, los estados, los municipios y al Distrito Federal, a órganos administrativos y a asociaciones privadas no gubernamentales, que pueden actuar de modo independiente o conjunto.

19 Esta solución ha sido recogida por el Derecho Brasileño en la tutela de intereses supraindividuales. Así, la cosa juzgada producirá efectos erga omnes salvo en el caso en que la demanda sea rechazada por insuficiencia de pruebas, caso en el que produce efectos secundum eventum litis. Cfr., en este sentido, Pellegrini Grinover, A., "El nuevo proceso brasileño del consumidor", en Estudios sobre Consumo, 25, 1992, pp. 13-24. En sentido contrario, Gidi, A., "Cosa juzgada en acciones colectivas", en La tutela de los derechos difusos, colectivos e individuales un una perspectiva comparada, Porrúa, México, 2003, pp. 273 y 274, señala que estos efectos secundum eventum litis se forman precisamente cuando la sentencia es favorable a la pretensión deducida, y no cuando es desfavorable, como suele señalar la doctrina. La sentencia tendrá una extensión de sus efectos de cosa juzgada de acuerdo a esta fórmula cuando la acción colectiva es acogida por el tribunal, de modo tal 
del proceso o los fundamentos de la acción, porque en estos casos no es posible iniciar un nuevo juicio.

El sistema brasileño se ha encargado de regular de modo especial la legitimación de las asociaciones privadas, porque se entiende que son representantes naturales de estos intereses supraindividuales. A diferencia de lo que sucede en la legislación española, no se les exigen requisitos de carácter administrativo, sino que sólo deben cumplir con dos requisitos, que consisten en que se halle legalmente establecida al menos por un año y la correspondencia entre los derechos protegidos y los fines institucionales de la organización.

En lo que respecta a la legislación española, el apartado tercero del artículo 11 de la Ley de Enjuiciamiento Civil exige a las asociaciones de consumidores, cuando los perjudicados son indeterminados o de difícil determinación, que sean "representativas".

Este requisito se contradice con lo dispuesto por el apartado primero del mismo artículo, ya que éste no impone ningún tipo de restricción en materia de legitimación, mientras que aquél establece un criterio de representatividad, sin que se haya establecido ningún mecanismo para determinar la existencia de la misma.

La finalidad de esta exigencia es asegurar, mediante el otorgamiento de legitimación a instituciones a las que el legislador considera de mayor estabilidad o seriedad, una correcta defensa procesal de estos intereses y derechos. Pero este requisito tampoco era necesario, porque tratándose de un interés supraindividual, la asociación de consumidores y usuarios defiende una posición jurídica propia, aunque compartida. Y la legitimación para instar la actuación jurisdiccional contra actuaciones ilícitas que afectan de forma común al interés legítimo de un grupo o categoría de personas se reconoce a esas personas físicas o jurídicas para pretender la tutela jurisdiccional de su esfera jurídica.

De lo que ha de depender propiamente la legitimación es de la afirmación de titularidad de un derecho o interés legítimo de quien activa el proceso. En el caso de las asociaciones, es su finalidad asociativa la que determina y delimita su ámbito de actuación.

Es decir, una asociación de consumidores deberá acreditar su calidad de tal para poder instar, por ejemplo, el cese de una publicidad o reaccionar de un acto de competencia desleal que afecten a los intereses difusos de aquellos ${ }^{20}$.

que dicha sentencia hará cosa juzgada erga omnes o ultra partes para tutelar el bien colectivo, vinculando a la comunidad o al colectivo titular del derecho supraindividual y vinculando también, positivamente y en su esfera individual, a los titulares de derechos individuales homogéneos que pertenecen a esa comunidad o colectivo. Ese sería el sentido, a juicio de este autor, de la extensión de los efectos de cosa juzgada secundum eventum litis.

${ }^{20}$ Cfr. Gutiérrez de Cabiedes, P., La tutela jurisdiccional de los intereses supraindividuales: colectivos y difusos, Aranzadi, Navarra, 1999, p. 207 y ss. En atención a lo señalado estima que el concepto de representación adecuada no es necesario para la defensa de intereses supraindividuales. 


\section{LA EXIGENCIA DE REPRESENTACión ADECUADA EN LA LEY CHILENA DE PROTECCIÓN DEL CONSUMIDOR}

El artículo $51^{21}$ de la ley se encarga de señalar quiénes están legitimados para iniciar una demanda en defensa de esos intereses.

Así, expresa que el procedimiento para la protección de intereses colectivos y difusos se iniciará por demanda, y que ésta podrá ser presentada por el Servicio Nacional del Consumidor (SERNAC) ${ }^{22}$; por una asociación de consumidores con una constitución de a lo menos seis meses de anterioridad a la presentación de la acción ${ }^{23}$ y que cuente con la debida autorización de su asamblea para hacerlo, o bien por un grupo de consumidores afectados en un mismo interés, que se encuentren debidamente individualizados y en un número que no sea inferior a 50 personas $^{24}$.

Al establecer el legislador ciertas exigencias para que una asociación de consumidores pueda iniciar un procedimiento para la defensa de intereses supraindividuales y según se desarrolla más adelante en el presente trabajo, introduce un criterio de representatividad adecuada $^{25}$ que resulta fundamental en los sistemas anglosajones de las class actions y

${ }^{21}$ Creemos también que hubiese sido interesante legitimar a otras entidades legalmente constituidas, distintas de las Asociaciones de Consumidores, que contemplaran entres sus fines la protección, educación y defensa del consumidor.

${ }^{22}$ La calidad del SERNAC como sujeto legitimado merece algunas observaciones, por cuanto no sólo se limita a la posibilidad de deducir acciones de tutela colectiva, sino que también el legislador le ha otorgado la posibilidad de intervenir voluntaria o forzadamente en este tipo de procesos, como se desprende de los artículos 57 letra g y 53 B, ambos de la LPC. Genera también problemas desde el punto de vista de la igualdad procesal, por cuanto no se le aplican las sanciones previstas para los litigantes temerarios.

${ }^{23}$ Este requisito está también previsto en otras legislaciones, como la brasileña. Tiene por objeto favorecer a las organizaciones que tengan una duración efectiva en la protección de los derechos de los consumidores y prevenir que se produzcan abusos contra los demandados o el perjuicio de los miembros ausentes.

${ }^{24}$ La regulación de este supuesto de legitimación, a juicio de la doctrina, es muy poco satisfactoria e incluso, luego de la entrada en vigencia de la Ley $\mathrm{N}^{\circ}$ 19.946, parte de ella sigue negándola. Lo que diferencia al grupo de las entidades legalmente constituidas es su característica de aposterioridad, porque sólo surge tras el acto que provoca el conflicto jurisdiccional y cobra existencia con ocasión de la afectación ilícita y dañosa de los derechos o intereses de cada uno de sus miembros, que es lo que les otorga la cohesión. En cambio, las entidades legalmente constituidas tienen existencia propia y anterior a la producción de los hechos que motivan el proceso, actuando en el tráfico por medio de ciertos sujetos que serán los que luego comparezcan por dicha entidad en juicio. Esta norma encuentra su antecedente más próximo en el artículo $1^{\circ}$ de la Constitución, que reconoce y ampara a los grupos intermedios y en el derecho de asociación, contemplado en el artículo $19 \mathrm{n}^{\circ} 15$ del Texto Constitucional.

25 También parece estar pensando en ella cuando en el artículo 8 letra e establece entre las funciones de la asociación de consumidores el "representar tanto el interés individual, como el interés colectivo y difuso de los consumidores ante la autoridades jurisdiccionales o administrativas, mediante el ejercicio de las acciones y recursos que procedan”. Hacemos presente esta observación porque normalmente la asociación actuará provista de una legitimación ordinaria y no en representación de un tercero, lo que quiere decir fundamentalmente que la Asociación será la parte en el proceso con todas las consecuencias que ello conlleva. Creemos que en este sentido resultaba más exacta la redacción que daba la Ley $\mathrm{N}^{\circ} 19.496$ en su artículo $8^{\circ}$ letra d a la función de "representar a sus miembros y ejercer las acciones a que se refiere esta ley en defensa de aquellos consumidores que le otorguen el respectivo mandato”. 
de las representative actions, y que otras legislaciones como la brasileña han adoptado con éxito. Sin embargo, en legislaciones pertenecientes al derecho continental, especialmente en el derecho europeo ha sido criticado con dureza.

Consagra también la legitimación de un grupo de 50 o más consumidores afectados para iniciar un procedimiento de este tipo. La regulación de este supuesto de legitimación, a juicio de la doctrina, es muy poco satisfactoria e incluso, luego de la entrada en vigencia de la Ley $\mathrm{N}^{\circ} 19.946$, parte de ella sigue negándola ${ }^{26}$.

La ley no define lo que debe entenderse por "grupo de consumidores afectados", pero, siguiendo a la doctrina, entendemos que lo hay "cuando un determinado acto afecte de forma global, genérica y solidaria a los intereses de una colectividad determinada o indeterminada de personas; es decir, en esta expresión deben incluirse aquellos casos en los que lo que se pretende realmente es la tutela de un interés propio de grupo, entendido éste como interés genérico común a todos los miembros del mismo, que han sufrido una afección unitaria, y del cual son éstos titulares sólo en cuanto tales miembros del grupo" 27.

La disposición tampoco establece cómo se configurará la representación del grupo, y a quién corresponde dicha representación. Así, esta exigencia plantea problemas tales como quién será el representante del grupo, cómo se elegirá a dicho representante y si es necesario que conste el consentimiento expreso de todos los que conforman el grupo en relación con el otorgamiento del poder.

El legislador en esta materia ha establecido una excepción en relación con la acreditación de la legitimación del SERNAC, al disponer en el artículo 51 n 4, que "cuando se trate del Servicio Nacional del Consumidor o de una Asociación de consumidores, la parte demandante no requerirá acreditar la representación de consumidores determinados del colectivo en cuyo interés actúa”.

\section{LA EVALUACión DE LA REPRESENTATIVIDAD ADECUADA EN LA JURisprudencia de la Corte Suprema}

\subsection{Antecedentes de la decisión}

La Corte Suprema ha sentado el criterio sobre el control de la representatividad adecuada de las asociaciones de consumidores y usuarios en dos fallos, pronunciándose

${ }^{26}$ Creemos que la exigencia de un número mínimo de afectados que conformen el grupo no constituye un requisito de legitimación, sino que de capacidad para que el grupo sea parte, y una vez cumplido este requisito de capacidad se encontrará debidamente legitimado. También obedece esta exigencia a la utilización del criterio de la suficiencia de representación del grupo, en atención a que los efectos de la sentencia se extenderán a quienes no hayan sido parte en el proceso. Además deben encontrarse debidamente individualizados los miembros que conformen este grupo.

${ }^{27}$ Gutiérrez de Cabiedes, P., La tutela..., op. cit., pp. 308-309. 
sobre los recursos de casación en el fondo ${ }^{28}$ interpuestos por la parte demandante en los procesos iniciados en contra del Banco de Chile y en contra del Bank Boston N.A. por la Organización de Consumidores y Usuarios de Chile, ODECU ${ }^{29}$.

En la demanda interpuesta contra el Banco de Chile ${ }^{30}$, la asociación de consumidores solicita al tribunal de primera instancia que la acción colectiva sea admitida a tramitación, declarándose su admisibilidad de acuerdo a lo señalado en el artículo 52 de la Ley $\mathrm{N}^{\circ} 19.496$, por haber el demandado infringido las disposiciones de la ley de protección al consumidor afectando el interés colectivo ${ }^{31}$.

La demandada solicita se declare la inadmisibilidad de la acción intentada, en razón de que sería inaplicable la Ley $N^{\circ} 19.496$, ya que de acuerdo a lo dispuesto por el artículo $2^{\circ}$ bis, debe aplicarse al caso concreto la normativa contenida en la Ley General de Bancos, DFL 252 de 1960. En subsidio de dicha solicitud, expone que la demanda debe ser declarada inadmisible por cuanto la actora no cumple con ninguno de los requisitos que contempla el artículo 52 de la Ley $\mathrm{N}^{\circ} 19.496^{32}$.

El fallo de primera instancia, de fecha 23 de mayo de 2007, declaró la inadmisibilidad de la acción interpuesta, en atención a que la conducta perseguida no afecta el interés colectivo de los consumidores, así como tampoco hay precisión de las consideraciones de hecho o derecho, pues la demanda se elabora en base a hipótesis y no sobre conductas concretas. Señala que esta omisión se constata de la sola lectura de la demanda, ya que no se indica en qué caso específico se haya incurrido en las infracciones que se le imputan a la demandada, de modo tal que la relación de hechos se limita a hacer referencias genéricas en base a simulaciones. Señala el tribunal que esta omisión importa también la falta de legitimación activa, ya que si no es posible determinar que los integrantes de la Asociación demandante hayan sido afectados por los actos del Banco, la Asociación no estaría legitimada para demandar la defensa de los derechos afectados, ya que no habrían derechos afectados.

La Corte de Apelaciones de Santiago, en sentencia de fecha 13 de noviembre de ese mismo año, confirmó la sentencia de primera instancia, indicando que lo que debe

${ }^{28}$ Recursos de Casación en el fondo roles nº 601 de 2008 y 1297 de 2008.

${ }^{29}$ Sobre el procedimiento para la defensa colectiva de consumidores y usuarios, vid. Aguirrezabal Grünstein, M., "El procedimiento para la defensa de intereses colectivos y difusos de consumidores y usuarios en la ley de protección del consumidor", en La protección de los derechos de los consumidores en Chile, Cuaderno de Extensión Jurídica, Facultad de Derecho, Universidad de los Andes, Santiago, 2006, pp. 143-173.

30 Juicio seguido ante el Décimo Tercer Juzgado Civil de Santiago, causa rol 19.881-2006.

31 Básicamente, la demandante solicita: Declarar nulas ciertas cláusulas contractuales que ponen de cargo del cliente los costos legales de la operación de crédito hipotecario; declarar nula la cláusula de liberación de rendir cuenta de los dineros cobrados; declarar que el Banco infringió el artículo 28 de la ley; declarar que los clientes deben recibir la rendición de cuenta de los dineros y condenar al Banco de Chile a pagar las correspondientes indemnizaciones; ordenar las indemnización sin necesidad de la comparecencia personal de los clientes y ordenar el cese de la política de cobros excesivos e ilegales.

32 Alega como argumentos para declarar la admisibilidad de la acción el hecho que como motivo de inadmisibilidad la falta de personería, acuerdo y autorización para demandar 52 letra a; que la conducta no afecta el interés colectivo 52 letra b; que no se precisan las consideraciones de hecho ni de derecho 52 letra c y porque no concurre la necesidad procesal para la aplicación del procedimiento colectivo 52 letra d. 
analizarse en el caso en concreto es si existe o no la debida autorización de la asamblea para demandar. La Corte concluye que, en razón de la excepcionalidad que importa el que pueda accionarse colectivamente, la autorización que debe darse para tal efecto debe contar con el mayor número de elementos de convicción para ponderar la conveniencia de ello; señala el tribunal que "autorización debida" es sinónimo de decisión informada y justificada y que nada de esto aconteció en la asamblea.

Como consecuencia de lo anterior, si la autorización no es debida, no puede considerarse que la demanda interpuesta sea la manifestación de la voluntad real de los miembros de la asociación y, por ende, al no existir autorización, no hay legitimado activo.

En lo que respecta a la demanda interpuesta por la ODECU en contra de Bank Boston N.A ${ }^{33}$, el actor solicita se declare admisible la acción en conformidad a lo dispuesto en el artículo 52 de la Ley $\mathrm{N}^{\circ} 19.496^{34}$. En este procedimiento colectivo, al igual que en la causa ODECU con BANCO de CHILE, la controversia acerca de la admisibilidad de la acción que motiva la interposición del recurso de casación en el fondo radica en el análisis del requisito contemplado en la letra a) del artículo 51 de la ley de protección al consumidor, esto, toda vez que el demandado ha solicitado el rechazo de la acción deducida, asilándose en lo establecido en el artículo 52 en relación con la norma del 51 letra b) de la ley en comento, es decir, la falta de legitimación activa de la demandante, debido a que la Asociación demandante no habría cumplido con el requisito de contar con la debida autorización de su asamblea, basándose en el incumplimiento de los requisitos estatutarios de quórum suficiente para sesionar, y la falta de personería del presidente de la Asociación actora, de lo que se sigue que la demandada pretende enervar un requisito de admisibilidad de la acción.

En el fallo de primera instancia, de fecha 13 de abril de 2007, y siguiendo el mismo criterio anteriormente señalado, el tribunal declaró la inadmisibilidad de la acción intentada por carecer la Organización demandante de legitimación activa por defectos formales en la convocatoria a la asamblea y en la legalidad de la designación de su presidente, así como también señala que los derechos no han sido ejercidos por aquellos clientes vinculados con la entidad demandada, pues conforme a las declaraciones de los testigos, no se revelan en sus testimonios el compromiso y vinculación del solicitante con la situación expuesta en el libelo.

La Corte de Apelaciones de Santiago, en sentencia de fecha 20 de noviembre de ese mismo año, confirmó el fallo de primera instancia, declarando la inadmisibilidad de la acción intentada en base a la inexistencia en el libelo del requisito consagrado en la letra a) del artículo 52. Señala este tribunal que la actora acompañó la copia correspondiente al acta de la asamblea en que se adoptó tal acuerdo; en dicha asamblea el presidente justificó la necesidad de que los socios presentes otorguen mandato especial al Directorio

33 Juicio seguido ante el Trigésimo Juzgado Civil de Santiago, causa rol 19.914-2006.

${ }^{34}$ En concreto solicita se declare: la nulidad de la cláusula contractual que establece de cargo del consumidor los costos legales de la operación de crédito hipotecario; el establecimiento del porcentaje en que debe concurrir cada cliente al soportar los gastos y la declaración de nulidad de la cláusula de liberación de rendir cuenta de los dineros cobrados, solicitando una reparación a favor de todos los clientes del banco. 
para autorizar la ejecución de eventuales acciones de clase, pero que en dicha acta se autoriza de modo genérico y, utilizando el mismo argumento que en el fallo dictado por el mismo Tribunal a propósito de la causa ODECU con BANCO DE CHILE, agrega que en razón de la excepcionalidad que importa el accionar colectivamente, la autorización para tales efectos debe ser otorgada con el mayor número de elementos de convicción para ponderar la conveniencia en el ejercicio de la acción, concluyendo el sentenciador que la autorización debida debe ser informada y justificada.

\subsection{Criterio aplicado por la Corte Suprema en la calificación de la representatividad de las asociaciones de consumidores}

El criterio de la Corte Suprema en este aspecto de la temática fue similar en ambos fallos, debiendo destacarse ciertos aspectos relevantes contenidos en las decisiones de nuestro máximo tribunal para pronunciarse sobre la admisibilidad de las acciones interpuestas.

En este orden de ideas, cabe destacar lo que sigue:

a) Importancia de reconocer la necesidad de controlar la calidad del representante:

La Corte Suprema, pronunciándose sobre los recursos de casación interpuestos, ha reconocido la importancia de controlar la legitimación del demandante en un proceso colectivo, en especial si se trata de una asociación de consumidores, quienes resultan estar naturalmente llamados a la defensa de esta clase de intereses.

La protección de los derechos transindividuales supone el abandono de esquemas tradicionales de protección jurisdiccional en que se ha exigido la existencia de un interés personal y directo en el resultado del proceso, lo que no había permitido hasta ahora la protección de intereses que pertenecen a un grupo.

Las reglas de la legitimación y de la cosa juzgada se encuentran necesariamente vinculadas, y en ambas existe la necesidad de proteger los intereses de los miembros ausentes. En este sentido, si la sentencia que se pronuncia en un procedimiento colectivo resulta obligatoria incluso para aquellos que no hayan tenido intervención en el proceso, el legislador y el órgano jurisdiccional deben estar en condiciones de determinar quién es capaz de representar adecuadamente sus intereses en el tribunal.

b) Representación de los intereses de consumidores y usuarios por parte de las asociaciones

\section{b.1) El rol de las asociaciones de consumidores en la protección de los derechos de grupo}

Las asociaciones de consumidores han adquirido gran importancia en la defensa de los derechos e intereses de grupos de consumidores y usuarios. Ello porque constituyen una instancia intermedia entre el Estado como protector del interés público y el individuo. 
Por lo mismo, la Ley de Protección del Consumidor establece una serie de exigencias y requisitos que dicen relación especialmente con su finalidad y objeto. En este sentido, la asociación de consumidores debe contar con un programa bien definido, puesto que sólo se les permite la promoción de acciones de esta naturaleza cuando se trata de proteger intereses relacionados con los fines institucionales establecidos en sus estatutos.

Constituyen un representante natural del grupo por cuanto la defensa de derechos transindividuales requiere de una legitimación que vaya más allá de un individuo.

b.2.) Diversas posiciones de la asociación de consumidores en relación con la defensa del interés difuso o colectivo

Atendiendo a la naturaleza de la situación jurídica cuya tutela se pretende y de la que depende la posición que la organización ocupa en el proceso, deben distinguirse varios supuestos: algunos han considerado que para que exista legitimación de la asociación de consumidores y usuarios es necesario que al menos uno de sus miembros sea afectado, porque en otro caso atribuirle legitimación no tiene sentido. Cumplida esta exigencia, puede ejercitar la acción en beneficio de sus asociados y también de quienes no lo sean, sin que para ello le deba ser exigido que haya procedido a configurar y determinar el grupo con la mayoría de sus integrantes, como sí ocurre cuando se trata de otorgarle legitimación al grupo.

Cuando la asociación de consumidores y usuarios actúa en defensa de un derecho de la propia asociación, no se presentan mayores dificultades, porque se trata de un supuesto de legitimación ordinaria en defensa de un derecho de naturaleza individual, privativo de la organización, que incluso puede no tener relación con actos de consumo ${ }^{35}$.

En segundo lugar, la asociación de consumidores y usuarios puede actuar en defensa de un derecho individual de uno o varios de sus asociados, pero siempre tratándose de situaciones jurídicas individuales. En este caso, y aunque tampoco existe desarrollo legislativo de este supuesto podemos señalar que no estamos ante un supuesto de legitimación para la defensa de intereses supraindividuales, puesto que lo que existe son derechos individuales que pueden incluirse en la denominación de "intereses colectivos" 36.

Se trataría de una "legitimación ad processum, en cuanto a que la asociación puede actuar desde luego en el proceso en defensa de tal derecho individual, pero lo hace en realidad en representación y con el consenso del o de los concretos titulares y únicos legitimados "ad causam" para instar la defensa de sus derechos y disponer de ellos" 37.

${ }^{35}$ En este mismo sentido, Montero Aroca, J., La legitimación en el proceso civil (intento de aclarar un concepto que resulta más confuso cuanto más se escribe sobre él, Civitas, Madrid, 1994, p. 67, Bellido Penadés, R., "La tutela de los intereses de los consumidores en la nueva Ley de Enjuiciamiento Civil”, Tribunales de Justicia, 2002 II, p. 6, y Gutiérrez de Cabiedes, P., “Artículo 11...”, op. cit., p. 149. Puede decirse que la doctrina no presenta ningún tipo de conflicto en este aspecto.

${ }^{36}$ Si nos atenemos, por ejemplo, a la nomenclatura que utiliza la legislación española.

${ }^{37}$ Gutiérrez de Cabiedes, P., “Artículo 11...”, op. cit., p. 153. La Corte Suprema de los Estados Unidos ha considerado que para una asociación se encuentre legitimada para obrar en un procedimiento colectivo, debe demostrar que uno o más de sus asociados ha resultado lesionado por la conducta del demandado. El mero interés propio de la organización es insuficiente para que pueda considerarse legitimada para actuar. Cfr. en este sentido, Sierra Club v. Morton, U.S. n. 405, 1972, p. 727. 
Otros consideran que se trata de un supuesto de legitimación extraordinaria, aunque luego ellos mismos señalan que la asociación requiere contar con la voluntad del afectado ${ }^{38}$, lo que resultaría contradictorio, porque la legitimación por sustitución no requiere de ninguna autorización, ya que se trata de un supuesto de reconocimiento legal que no depende de la autorización de la persona a la que se sustituye ${ }^{39}$.

De este modo, "la calificación dogmática de este supuesto depende del significado que se dé a la legitimación por sustitución. De los supuestos mayoritariamente aceptados como de sustitución procesal puede deducirse el común denominador de la existencia de una relación jurídico-material conexa entre sustituto y sustituido. Y no existe aquí tal concatenación de relaciones jurídico-subjetivas por la que la asociación pueda ser considerada acreedora (o algo semejante) del asociado. Sólo si se entendiera la sustitución como una cierta interdependencia de intereses y se tomara como interés de la asociación el correcto desarrollo del consumo en general podría comprenderse tal calificación para esta situación. Pero no puede perderse de vista que se está aquí discutiendo sobre derechos individualizados de concretas personas y que el aludido interés genérico que pudiera existir de la asociación en el consumo se manifiesta precisamente en otro de

38 En esta línea de pensamiento, por ejemplo, López-Fragoso Álvarez, T., "Las partes”, en Gimeno Sendra, V., (dir.), Proceso civil práctico, La Ley, Madrid, 2004, pp. 2-107, 2-108 y 2-116, para quien éste constituye un supuesto de legitimación extraordinaria y representativa. Representativa porque se legitima a la asociaciones de consumidores y usuarios "para defender en juicio los derechos e intereses de sus asociados", y extraordinaria en el sentido de titularidad de un derecho procesal, puesto que constituye el reconocimiento de un derecho a intervenir en un proceso ajeno por los efectos reflejos que la sentencia puede producir sobre sus propias relaciones jurídicas. También Cachón Villar, P., "El acceso a la jurisdicción civil I: la titularidad de derechos e intereses legítimos: legitimación de las partes. Intervención de terceros. Protección de intereses difusos", en Principios constitucionales en el proceso civil, Consejo General del Poder Judicial, Madrid, 1993, pp. 60-61, quien señala que se estaría ante "un supuesto de legitimación por sustitución. Debe entenderse que, en todo caso, la asociaciones de consumidores y usuarios precisa de la autorización del correspondiente asociado para deducir judicialmente la pretensión”, De la Oliva Santos, A., Derecho procesal civil, $4^{a}$ edición, Centro de Estudios Ramón Areces, Madrid, 1997, p. 133, quien entiende que se trata de una legitimación representativa porque "aunque la asociación o el grupo no sea en absoluto, técnicamente, un representante -ni material ni procesal- de los consumidores y usuarios, parece poco dudoso que la ley permite el ejercicio de derechos ajenos en razón de una cierta representación social” y Garnica Martín, J., “Artículo 11. Legitimación para la defensa de derechos e intereses de consumidores y usuarios”, en Fernández-Ballesteros, M., Rifá Soler, J., Valls Gombau, J. (coords), Comentarios a la Nueva Ley de Enjuiciamiento Civil, Iurgium, Barcelona, 2000, p. 168, que señala que "en cuanto a la legitimación para la defensa de los derechos de sus asociados, se suele considerar que se está ante un supuesto de simple representación, pero no estamos de acuerdo con que ello sea así, porque el representante actúa en nombre de otro, que es quien en realidad es parte, y en estos casos no cabe la menor duda de que parte procesal es la propia asociación y no sus miembros. En sentido impropio sí cabe hablar de representación, y así se afirma que quien ejercita la acción de grupo adquiere una "representación paraorgánica de la clase". En este sentido sí podría afirmarse que la asociación de consumidores y usuarios se convierte en representante paraorgánico de todos los integrantes de la clase, en tutela de cuyos intereses individuales actúa. Pero eso no significa que se esté propiamente ante una representación, ni legal, ni voluntaria, sino que se está simplemente ante un supuesto particular de legitimación extraordinaria”.

39 Por ello es que podemos hablar de representación tácita, pero no de legitimación presunta. 
los supuestos legales de legitimación: el otorgado para la defensa de los llamados por el legislador intereses generales de los consumidores" 40 .

El problema central radica en plantearse si se quiere atribuir a la asociación de consumidores la facultad de actuar y disponer libremente de los derechos individuales de los consumidores. Parece una posición peligrosa y contraria a los fines de la asociación, puesto que ésta presenta una finalidad de servicio que debe estar siempre subordinada a la decisión del sujeto individual perjudicado.

En cuanto a la forma de otorgar el consentimiento por parte del asociado, se planteaban dos alternativas: exigir el correspondiente apoderamiento expreso, lo que resulta rígido y dificulta la eficaz protección de los intereses de los asociados ${ }^{41}$ y considerar como suficiente un otorgamiento tácito, entendiendo que el asociado ha otorgado la representación en el acto de afiliación a la asociación, con lo que bastaría con acreditar la calidad de asociado del consumidor o usuario perjudicado. Esta segunda alternativa presenta el problema que el asociado puede incluso desconocer el ejercicio de las acciones con las implicaciones que ello conlleva. Por eso, para parte de la doctrina, resulta preferible una forma ecléctica que flexibilice la forma de conferir la representación y garantice el conocimiento por el representado de la interposición en su nombre de la pretensión indemnizatoria.

La tercera posibilidad es que la asociación de consumidores actúe en defensa de un interés colectivo o difuso. La Ley $\mathrm{N}^{0} 19.955$ incorpora a su texto la terminología de intereses difusos y colectivos atendiendo al criterio del grado de determinación de los interesados, sin apreciar la diferencia entre estas clases de intereses supraindividuales y lo que constituyen derechos individuales, también denominados intereses individuales homogéneos. Lo anterior es el resultado de no haber considerado la naturaleza jurídica de la posición afectada (interés legítimo supraindividual o derecho subjetivo patrimonial a la reparación de un perjuicio personal), ni de haber tenido en cuenta estos aspectos al momento de articular los mecanismos de tutela que no son precisos ni en su configuración ni es su funcionamiento ${ }^{42}$.

Las legislaciones más avanzadas en materia de protección de consumidores sí reconocen esta diferencia entre los intereses supraindividuales y los intereses individuales

${ }^{40}$ Gutiérrez de Cabiedes, P., “Artículo $11 \ldots$, op. cit., p. 154.

${ }^{41}$ Cfr. Bellido Penadés, R., "La tutela de los intereses...", op. cit., pp. 6-7, y del mismo autor, El proceso civil sobre competencia desleal y propiedad industrial, Civitas, Madrid, 2002, p. 70, en donde también, y en relación con la Ley sobre Competencia Desleal, se inclina por un apoderamiento expreso que permita acreditar el consentimiento del consumidor asociado y su voluntad de reclamar unos determinados daños o perjuicios. Señala que con la nueva Ley de Enjuiciamiento Civil esta opción podría alcanzarse mediante una interpretación analógica de los artículos 11.2 y 15.1. y 2 Ley de Enjuiciamiento Civil respecto de cualquier asociación de consumidores o entidad legalmente constituida.

42 Para un estudio en extenso de la noción de interés supraindividual, vid. Aguirrezabal Grünstein, M., "Algunas precisiones en torno a los intereses supraindividuales colectivos y difusos", Revista Chilena de Derecho, volumen XVIII, n 1, 2006, pp. 21-39. 
homogéneos o plurisubjetivos, destacando la norteamericana, la francesa y la brasileña ${ }^{43}$. Corresponden a una categoría de intereses que ha sido elaborada en los países del Common Law y principalmente por la legislación brasileña, que como ya señalamos, la introduce en el Código del Consumidor de 1990. Son derechos individuales que por efectos prácticos se hacen "accidentalmente colectivos" 44 , y que han sido definidos como "una compilación de derechos subjetivos individuales, marcados por la nota de divisibilidad, del cual es titular una comunidad de personas indeterminadas más determinables, cuyo origen está en alegaciones de cuestiones comunes de hecho o de derecho" ${ }^{45}$.

Estos intereses se distinguen de los difusos y colectivos en que aquellos son verdaderos derechos individuales, privativos e indisponibles por terceros, pero que pueden existir en número plural y tener un origen fáctico común y un contenido sustantivo homogéneo ${ }^{46}$.

Presentan dos características esenciales para su tratamiento colectivo: su homogeneidad, que le viene dada por su origen $\operatorname{común}^{47}$ y su divisibilidad, puesto que nos

${ }^{43}$ Brasil es el país que de mejor modo ha atendido al fenómeno de la protección de situaciones jurídicas plurisubjetivas, es decir, respecto de intereses supraindividuales tanto colectivos como difusos y también respecto de los intereses individuales homogéneos. La distinción entre estos tipos de situaciones jurídicas es explícita y se encuentra consagrada en la Ley $\mathrm{N}^{\circ}$ 8.078, de 11 de septiembre de 1990, que aprueba el Código de Defensa del Consumidor. La Ley $\mathrm{N}^{\circ} 7347$, de 1985, se ocupaba de lo que ella denominaba los "intereses supraindividuales", distinguiendo los intereses difusos y los intereses colectivos" y luego la Ley No 8.078 se preocupó de regular las "Acciones Colectivas para la defensa de los intereses individuales homogéneos”, a lo cual se dedica el Capítulo II del Título III, que se denomina "De la defensa del consumidor en juicio". La legislación francesa también apuntó la referencia en la ley relativa a las acciones jurisdiccionales de las asociaciones de consumidores, en cuyo capítulo II se articula lo que se ha llamado "acción en representación conjunta” y luego recogida en el Código Francés del Consumidor.

${ }^{44}$ Cfr. Barbosa Moreira, M., “Tutela jurisdiccional dos intereses colectivos ou difusos”, en Temas de direito processual, Saraiva, São Paulo, 2000, pp. 195-196. Los distingue así de los supraindividuales, a los que califica como "esencialmente colectivos", citado por Watanabe, K., "Acciones colectivas: cuidados necesarios para la correcta fijación del objeto litigioso del proceso”, en Gidi A., Ferrer Mac-Gregor, E.; (coords.), La tutela de los derechos difusos, colectivos e individuales homogéneos. Hacia un Código Modelo para Iberoamérica, Porrúa, México, 2003, p.3. Este mismo autor los califica como "ontológicamente individuales, pero que son tutelados colectivamente, por razones de estrategia de tratamiento de conflictos".

${ }^{45}$ Gidi, A., "Derechos difusos, colectivos e individuales homogéneos”, en Gidi A., Ferrer Mac-Gregor, E. (coords.), La tutela de los derechos difusos, colectivos e individuales homogéneos. Hacia un Código Modelo para Iberoamérica, Porrúa, México, 2003, p.35.

${ }^{46}$ Cfr. Gutiérrez de Cabiedes, P., La tutela..., op. cit., p. 441. El autor señala que, por ejemplo, la difusión de una publicidad engañosa o la comercialización de un producto defectuoso dan lugar a un interés difuso, mientras que la falta de higiene o seguridad en una fábrica dará lugar a un interés colectivo. Serán derechos individuales plurales aquellos de que son titulares quienes han adquirido un bien que no responde a las cualidades anunciadas o contratadas.

${ }^{47}$ No es requisito que entre las personas titulares de este tipo de derechos exista una relación jurídica anterior, puesto que el vínculo con la parte contraria nacerá precisamente de la lesión, relación que además es individual y que afectará de modo distinto la esfera jurídica de cada uno de ellos. El origen común en todo caso puede ser más o menos remoto. Mientras más remoto menos homogéneos serán estos derechos. Tampoco este origen común implica necesariamente una unidad de hecho temporal, lo que significa que no es necesario que el hecho creador de los derechos sea el único o el mismo en todos los derechos. Lo esencial será que nos encontremos ante situaciones jurídicamente iguales, aunque los hechos sean diferentes. 
encontramos ante derechos que pueden ejercerse individualmente pero respecto de los cuales resulta más conveniente su defensa colectiva ${ }^{48}$.

La diferencia entre los intereses supraindividuales y los plurisubjetivos tiene mucha importancia desde el punto de vista práctico, puesto que su tratamiento procesal es distinto por tratarse los segundos de derechos subjetivos clásicos, lo que implica que en lo que respecta a la legitimación, los límites subjetivos de eficacia de la sentencia y la indemnización de los perjuicios dependerán de las circunstancias personales del titular del derecho ${ }^{49}$.

En cuanto a la legitimación otorgada a la asociación para la defensa de intereses colectivos y difusos, sí constituye un caso con fundamento en la finalidad asociativa establecida en sus estatutos, ya que, "cuando un acto incide en las necesidades específicas de una categoría de sujetos referidas al consumo (salubridad, información veraz, libre concurrencia, equilibrio de las prestaciones, etc.), que es su función proteger, afecta a un bien jurídico en el que la organización está interesada, por tratarse de su finalidad estatutaria, manifestación inequívoca de un interés legítimo. Esa finalidad de la organización (para la cual se ha formado y que constituye su razón de ser) sirve, en virtud del principio de especialidad inherente a las personas jurídicas, de fundamento a su interés legítimo; es el punto de conexión subjetivo-objetiva constitutivo de un interés legitimador, de una situación jurídico-subjetiva protegida y legitimante" ${ }^{\text {. }}$.

No se trata, en todo caso, de un supuesto de legitimación extraordinaria, como ha afirmado parte de la doctrina ${ }^{51}$, porque la asociación procura la tutela de un derecho propio, y tampoco se trata de un supuesto de representación, porque la asociación es parte y no representante.

Tampoco se trata de un caso de legitimación popular, porque aquélla se funda en un interés legítimo, y ésta en un interés en la legalidad, no siendo precisa la invocación de una calificación subjetiva especial; porque la primera se otorga a una determinada categoría o colectividad, mientras que la segunda se otorga a todos los ciudadanos.

${ }^{48}$ Cfr. Pellegrini Grinover, A., "I processi collettivi del consumatore nella prassi brasiliana”, en Rivista di Diritto Processuale 1994, pp. 106-114. Agrega que la distinción fundamental se manifiesta en que en los intereses supraindividuales la solución del litigio es la misma para todos, debido a la indivisibilidad del objeto del proceso y en los segundos, en cambio, la solución no es la misma para todos, precisamente porque el objeto del proceso es divisible.

En sentido contrario, Gutiérrez de Cabiedes, P., La tutela..., cit. n. 18, p. 450, quien considera que la distinción no debe basarse en el criterio de la divisibilidad, sino en la existencia o inexistencia de monopolio en la disposición material y procesal de la situación jurídica que se tutela.

${ }^{49}$ Hay que estar también a la forma en que se formula la solicitud de tutela jurisdiccional y los fundamentos de la demanda colectiva, para saber si nos encontramos ante una verdadera demanda para la tutela de intereses supraindividuales o si bien se trata de tutelar intereses individuales homogéneos.

${ }^{50}$ Gutiérrez de Cabiedes, P., "La nueva Ley de Enjuiciamiento Civil y los daños con múltiples afectados”, en Derecho del consumo. Acceso a la justicia, responsabilidad y garantía, Instituto Nacional del Consumo, Madrid, 2001, pp. 160-161.

${ }^{51}$ Cfr., en este sentido, Villar Fuentes, I., "Algunas reflexiones sobre la legitimación para la protección de los intereses de los consumidores y usuarios”, en Justicia, 2001, p. 7; López-Fragoso Álvarez, T., "Las partes", op. cit., p. 2-112 y De la Oliva Santos, A., Derecho Procesal..., op. cit., p. 133. 
Además, la primera existe en todos aquellos casos en que se dé una afección de situaciones jurídicas de esta naturaleza, mientras que la segunda requiere, por su excepcionalidad, de un reconocimiento explícito, limitándose el ejercicio de la acción a los supuestos en que la ley expresamente lo permita.

Tampoco se trata de un supuesto de representación, porque la asociación es parte y no representante.

El artículo $51 \mathrm{n}^{\circ} 1$ de la ley reconoce legitimación a las asociaciones de consumidores para la defensa de los intereses supraindividuales, pero luego en el número en comento entiende que esta Asociación actúa en representación de consumidores determinados del colectivo por el que actúa, de lo que resulta plantear dos cuestiones: una, es que si actúa en representación de consumidores determinados -nótese que la ley no habla de representación de los intereses de sus asociados, sino de consumidores pertenecientes a un colectivo, lo que quiere decir que la representación no se limita a los asociados- el sujeto legitimado y parte en el proceso no es la asociación sino el consumidor representado.

Luego, y siguiendo el criterio del legislador, la asociación nunca estaría ella misma legitimada para actuar, porque siempre actuaría en representación de un consumidor o de un conjunto de consumidores. El error proviene de la confusión entre la figura de representación y la legitimación, lo que ya hicimos notar. Normalmente la Asociación actuará provista de legitimación ordinaria y la representación sólo se producirá cuando se trate de la lesión de intereses que pertenezcan a los asociados de esta asociación legitimada para actuar. Así planteada la cuestión, no resulta tan simple la acreditación de la representación cuando no se trata de la representación de asociados, en que existe un otorgamiento de representación conjunta con el momento de la afiliación. En el resto de los casos, aunque se trate de consumidores determinados, la representación tendrá que acreditarse conforme a las reglas generales del procedimiento civil.

Es importante la afirmación anterior porque, como ya se señaló, la letra b) del no 1 del artículo 51 otorga legitimación a una Asociación de Consumidores, exigiéndole dos requisitos para entenderse legitimada: estar constituida a lo menos con seis meses de anterioridad a la presentación de la acción ${ }^{52}$ y contar con la debida autorización de su asamblea para iniciar un procedimiento de estas características.

c) El concepto de “debida autorización” para evaluar la configuración del requisito:

De la lectura crítica de ambos fallos se deduce que el estándar utilizado por la Corte Suprema para evaluar la calidad de la representación adecuada (legitimación) dice relación con el concepto de "debida autorización", que como ya hemos mencionado, exige como requisito el artículo $51 \mathrm{n}^{\circ} 1$ letra b) de la Ley.

En este sentido, la Corte ha procedido a establecer qué es lo que debe entenderse por "debida autorización" y las exigencias de dicho requisito.

52 Nos parece errada la utilización del término "acción". Debió haberse utilizado el de "demanda", porque indudablemente acción y demanda no son términos equivalentes. 
Ha señalado que en lo relativo a la autorización, el concepto de "debida", como adjetivo, implica que no cualquier habilitación permite la interposición de la demanda, sino que aquella que pueda ser calificada de pertinente para tales fines. Se requiere la firme y expresa voluntad manifestada en un sentido determinado, en que se toma partido con determinación, puesto que constituye el consentimiento para enfrentar todas las consecuencias y efectos de la medida acordada.

Considera la Corte que la declaración de la asamblea de la asociación de consumidores y usuarios, en ambos casos, expresada bajo la fórmula empleada en el acta respectiva, que se tuvo por inamoviblemente fijado, constituye la debida autorización a que hace referencia la ley.

En otros términos, la decisión adoptada en el caso en concreto permite ser calificada de esa forma, pues satisface las exigencias legales, tales como el hecho que la acción ha sido interpuesta por una Asociación de Consumidores, constituida con más de seis meses de anticipación y a la cual su asamblea facultó (procedimiento y órgano interno en que se radica la mayor representatividad).

En razón de todo lo anteriormente expuesto, considera el sentenciador que no puede forzarse el contenido "en términos de requerir un mayor número de elementos de convicción para ponderar la conveniencia de la interposición de la acción" 53 , los cuales no se especifican y lindan en la generalidad que descalifican. Agrega que el fallo de segunda instancia expresa que la autorización debe ser justificada e informada, pero en ningún caso se señala que debe entenderse por aquello, ni los requisitos que deben cumplirse para que la autorización cumpla con dichas exigencias.

El concepto de "debida autorización" debe reunir determinados presupuestos, en atención a si la finalidad es pública o colectiva y si ha contado con los requisitos formales exigidos por la ley, esto es, los seis meses de anticipación y la autorización de la asamblea, los que en la especie han concurrido.

En atención a los argumentos ya mencionados y en ambos procesos, la Corte Suprema procede a dictar sentencia de reemplazo, declarando admisible la acción colectiva y ordenando la prosecución del juicio en primera instancia.

Concordamos con el criterio de la Corte Suprema, en el sentido de que la exigencia de la representatividad adecuada se cumple a través de los requisitos de tiempo mínimo de constitución de la asociación y la autorización de la asamblea. Dichos requisitos son fácticamente comprobables por el órgano jurisdiccional, encontrándose este último impedido de requerir más elementos de convicción en esta etapa del proceso.

Creemos también que el criterio asentado por nuestro Tribunal Superior refleja de mejor manera el espíritu que el legislador tuvo en vista al momento de la reforma: favorecer el acceso del consumidor a la justicia.

53 Considerando décimo tercero de la sentencia pronunciada por la Corte Suprema, de fecha 6 de mayo de 2009. 


\section{BiBLIOGRAFÍA}

Barbosa Moreira, M., "Tutela jurisdiccional dos intereses colectivos ou difusos", en Temas de direito processual, Saraiva, São Paulo, 2000.

Bellido Penadés, R., "La tutela de los intereses de los consumidores en la nueva Ley de Enjuiciamiento Civil”, en Tribunales de Justicia, 2002.

Bonet Navarro, A., "Protección eficaz y acceso a la justicia de los consumidores", en Estudios sobre Consumo, 16, 1989.

Bujosa Vadell, L., "Artículo 11. Legitimación para la defensa de derechos e intereses de consumidores y usuarios”, en Gómez de Liaño González, F. (coord.), La Ley de Enjuiciamiento Civil, Forum, Oviedo, 2000).

Bujosa Vadell, L., La protección jurisdiccional de los intereses de grupo, Bosch, Barcelona, 1995.

CACHÓn Villar, P., "El acceso a la jurisdicción civil (I): la titularidad de derechos e intereses legítimos: legitimación de las partes. Intervención de terceros. Protección de intereses difusos", en Principios constitucionales en el proceso civil, Consejo General del Poder Judicial, Madrid, 1993.

Cappelletti, M., "Formaciones sociales e intereses de grupo frente a la justicia civil", en Boletín Mexicano de Derecho Comparado, 83, 1995.

De la Oliva Santos, A., Derecho procesal civil, $4^{\mathrm{a}}$ edición, Centro de Estudios Ramón Areces, Madrid, 1997.

Fleming, J., Hazard, G., Leubsdorf, J., Civil Procedure, $5^{a}$ ed., Ed. Foundation Press, New York, 2000.

Garnica Martín, J., "Artículo 11. Legitimación para la defensa de derechos e intereses de consumidores y usuarios”, en Fernández-Ballesteros, M., Rifá Soler, J., Valls Gombau, J. (coords.), Comentarios a la Nueva Ley de Enjuiciamiento Civil Iurgium, Barcelona, 2000.

GidI, A., "Derechos difusos, colectivos e individuales homogéneos", en Gidi A., Ferrer MacGregor, E. (coords.), La tutela de los derechos difusos, colectivos e individuales homogéneos. Hacia un Código Modelo para Iberoamérica, Porrúa, México, 2003.

GidI, A., "La representación adecuada en las acciones colectivas brasileñas y el avance del Código Modelo", en Gidi A., Ferrer Mac-Gregor, E. (coords.), La tutela de los derechos difusos, colectivos e individuales homogéneos. Hacia un Código Modelo para Iberoamérica, Porrúa, México, 2003.

Gidi, A., "Las acciones colectivas en los Estados Unidos", en Procesos colectivos. La tutela de los derechos difusos, colectivos e individuales en una perspectiva comparada, Porrúa, México, 2003.

GIDI, A., "Cosa juzgada en acciones colectivas", en Gidi A., Ferrer Mac-Gregor, E. (coords.), La tutela de los derechos difusos, colectivos e individuales homogéneos. Hacia un Código Modelo para Iberoamérica, Porrúa, México, 2003.

GonZÁlez Vaqué, L., "El Derecho de consumo: ¿una disciplina jurídica autónoma?”, en Estudios sobre Consumo, 22, 1991.

GutiérRez de Cabiedes, P., La tutela jurisdiccional de los intereses supraindividuales: colectivos y difusos, Aranzadi, Navarra, 1999.

Gutiérrez de Cabiedes, P., "Artículo 11. Legitimación para la Defensa de Derechos de Consumidores y Usuarios”, en Cordón Moreno, F. (coord.), Comentarios a la Ley de Enjuiciamiento Civil, Aranzadi, Navarra, 2001.

Gutiérrez de Cabiedes, P., "La nueva Ley de Enjuiciamiento Civil y los daños con múltiples afectados", en Derecho del consumo. Acceso a la justicia, responsabilidad y garantía, Instituto Nacional del Consumo, Madrid, 2001.

Klonoff, R., Bilich, E., Class Actions and Other Multi-Party Litigation: Cases and Materials, West Group, 2000. 
KLONOFF, R., “The Judiciary's Flawed Application of Rule 23's adequacy of representation requirement", 2004 Mich. St. L. Rev 671

López-Fragoso Álvarez, T., "Las partes”, en Gimeno Sendra, V., (dir.), Proceso civil práctico, La Ley, Madrid, 2004.

Montero Aroca, J., La legitimación en el proceso civil (intento de aclarar un concepto que resulta más confuso cuanto más se escribe sobre él), Civitas, Madrid, 1994.

Navarro Hernán, M., Partes, legitimación y litisconsorcio en el proceso civil, Colex, Madrid, 1998.

Pellegrini Grinover, A., "I processi collettivi del consumatore nella prassi brasiliana", em Rivista di Diritto Processuale, 1994.

Pellegrini Grinover, A., "El nuevo proceso brasileño del consumidor", en Estudios sobre Consumo, 25, 1992.

Rodríguez López, R., "Tutela jurisdiccional de los derechos de los consumidores y usuarios", en Actualidad Civil, 56, 1990.

Romero Seguel, A., "Algunos Aspectos Procesales de las Acciones para la Protección de los Consumidores", en Cuaderno de Extensión Universidad de los Andes, 7, Universidad de los Andes, Santiago, 1999.

Subrin, S., "Civil Procedure. Doctrine, practice, and Context", Aspen Law E Bussines, New York, 2000.

Tidmarsh, J., "Rethinking Adequacy of Representation", 87 Tex. L. Rev.

Villar Fuentes, I., "Algunas reflexiones sobre la legitimación para la protección de los intereses de los consumidores y usuarios", en Justicia, 2001.

Watanabe, K., Acciones colectivas: cuidados necesarios para la correcta fijación del objeto litigioso del proceso, en Gidi A., Ferrer Mac-Gregor, E. (coords.), La tutela de los derechos difusos, colectivos e individuales homogéneos. Hacia un Código Modelo para Iberoamérica, Porrúa, México, 2003.

Wright, C., "Class Actions", 47 FRD, 169, 1970. 